\title{
The effects of intercompany lending on the current account balances of selected economies in the Western Balkans
}

IVANA ĐUROVIĆ, M.A.*

Article**

JEL: F32

doi: $10.3326 /$ pse. 41.4 .2

\footnotetext{
* The author would like to thank two anonymous referees for their valuable comments and suggestions. This paper is based on the master's thesis "The Intercompany Lending Effects on the Current Account Balance: Case of Former Yugoslav Republics", defended in June 2017 at the Central European University in Budapest, under the mentorship of Professor Lajos Bokros, Ph.D.

${ }^{* *}$ Received: June 1, 2017

Accepted: October 31, 2017
}

The article was judged the best paper in the student category in the annual competition for the Prof. Dr. Marijan Hanžeković Prize for 2017.

Ivana ĐUROVIĆ

Central European University, Department of Economics, Nádor u. 13, 1051 Budapest, Hungary

e-mail: Durovic Ivana@alumni.ceu.edu

ORCiD: 0000-0001-7294-3022 


\section{Abstract}

This paper quantifies the effect of intercompany lending on the current account balances in the economies that previously made up the Socialist Federative Republic of Yugoslavia. This kind of transaction is a controversial part of the foreign direct investments, often criticised for its indebting nature and its involvement in tax evasion strategies. However, the data shows that in the post-crisis period it was the driving force of foreign capital inflow and investments in the region. For this study, a novel model averaging approach was employed, as it allows cross-country and country-specific analysis, and provides a sound basis for future policymaking. Additionally, as a way to overcome the limited data availability problem, and provide an additional robustness check, panel regression fixed effects for 17 CESEE economies was done. The results of both models are significant and indicate the stabilising effect of the observed transaction as it provided a steady inflow of funds.

Keywords: intercompany lending, foreign direct investment, Jackknife model averaging

\section{INTRODUCTION}

Intercompany lending, is a constituent part of foreign direct investments (FDI) (IMF, 2009) that represents a controversial element, frequently underestimated because of its indebting nature and involvement in tax evasion strategies. However, in this paper, the goal is to observe it from another perspective and determine the beneficial effect it had on the current account balances (CABs) of Western Balkan economies when the global financial crisis struck.

The effects of FDI have been the topic of many papers (Lim, 2001; Li and Liu, 2005; Hermes and Lensink, 2003; Borensztein, De Gregorio and Lee, 1998). Some find that, especially for transition economies, the presence of foreign investors has created positive externalities, and helped them to integrate into the world market (DiMauro, 2000), and some indicate that it has contributed to the restructuring of formerly state-owned enterprises (Estrin et al., 2009). Positive findings further spurred a vast literature about the FDI determinants in transition economies (Bevan and Estrin, 2004; Resmini, 2000). However, all papers observe FDI as a total and disregard the different nature of its components: equity investment (EI), reinvested earnings and intercompany lending (ICL).

The existing literature on ICL is mostly focused on corporate finance and the possibilities for transfer pricing. However, in this paper, we will shift focus onto the FDI nature of cross-border ICL and show that since the crisis hit the observed region, ICL became an essential element of total FDI inflow. Furthermore, it will explain that the magnitude of the effect differs and depends on the country's characteristics.

The contribution of this paper is that until now, at least to the best of the author's knowledge, no paper has analysed ICL in the region from this perspective. More- 
over, it quantifies the effect with the use of two models. The novel technique of model averaging is employed as the primary model, while the panel regression fixed effects model, serves as a robustness check. The former focuses on individual countries, provides separate estimates for each of them and enables crosscountry and country-specific analysis. Therefore, it can serve as a sound basis for policymaking.

The paper is organised as follows: the next section will give an overview of ICL. The occurrences in the post-crisis period that inspired this analysis are given in section 3. The econometric analysis will be explained in detail in section 4. Finally, the last part will contain the conclusion, potential policy recommendations and indicate the limitations of the study. Additionally, the appendix provides data that can be used for further analysis.

\section{INTERCOMPANY LENDING}

The power of multinational companies $(\mathrm{MNC})$ depends on their ability to make the most out of their global presence. Therefore, when deciding where to establish a new unit, they look for cost-cutting opportunities, such as tax reduction schemes (Devereux and Griffith, 1998; Barrios et al., 2009). ICL is a common part of these plans as it allows exploitation of the tax rate differentials to shift profit (Buettner and Wamser, 2007; Stewart, 1977) leaving both source and host countries with lower tax bases and tax revenues.

However, ICL should not be observed only as a part of a tax evasion strategy but also as a part of a risk-management strategy that MNC employ to optimise resources and protect previously invested funds. Since the outbreak of the financial crisis, risk aversion among investors has risen, leading to an increase in ICL (ECB, 2012). There are at least two reasons for this. First, affiliated companies located in emerging markets were faced with a tightening of credit conditions and were unable to obtain the necessary funds under conditions acceptable to them. Second, as EI represents pricier and riskier forms of capital, direct investors needed something that would allow them to finance their subsidiary while preserving flexibility. The solution was ICL since it provides a flow of funds for taffiliates, and at the same time, creates enough pressure to make them step up and work better in the crisis period.

The latter view fits better with the observed FDI nature of ICL. This dimension became noticeable only after the crisis when many posed the question regarding the sustainability of the benefits of FDI to emerging economies (Starnawska, 2015). Hebous and Weichenrieder (2010) noted that ICL amplified the stabilising role FDI had during the crisis. Moreover, data show that in Central, Eastern and South-eastern Europe (CESEE) in the aftermath of the crisis, the increase of ICL sustained total FDI, and stabilised capital flows (Gardo and Martin, 2010). That occurrence is precisely what this paper analyses, with the focus on the Western Balkan region. 
Before the crisis, CESEE countries, experienced positive growth rates. They were resilient until the first half of 2008 , since the region was not as exposed to subprime markets as developed countries (Gardo and Martin, 2010). However, in September 2008, the crisis spread to the whole financial sector, and growth rates started to decline.

Fast growth and return on investment that existed before 2008 created keen interest from foreign banks in the whole CESEE region. It is noteworthy that at the end of 2008 , almost $80 \%$ of the banking sector in this area was held by foreigners (Gardo and Martin, 2010). Although this type of vulnerability was not in focus before the crisis, it created significant liquidity problems after. The problem occurred when parent banks decided to withdraw funds from these markets so they could consolidate at home (Herrmann and Mihaljek, 2010). This spillover had several implications. First, parent banks were not able to extend the same amount of loans as earlier to their CESEE subsidiaries. Secondly, the interbank market was disrupted (ECB, 2012). Subsequently, this reduced the available funds of domestic banks, which reacted by tightening credit conditions. Finally, problems were transferred to the private sector, which was faced with liquidity issues.

Conversely, the share of the ICL flows in the total FDI inflow increased right after the start of the global financial crisis. Additionally, the same situation repeated itself when the Euro debt crisis began. Figure 1 highlights this in the region and allows comparison with similar movements in the advanced economies.

\section{Figure 1}

The share of ICL in the total FDI, inflow in bn USD

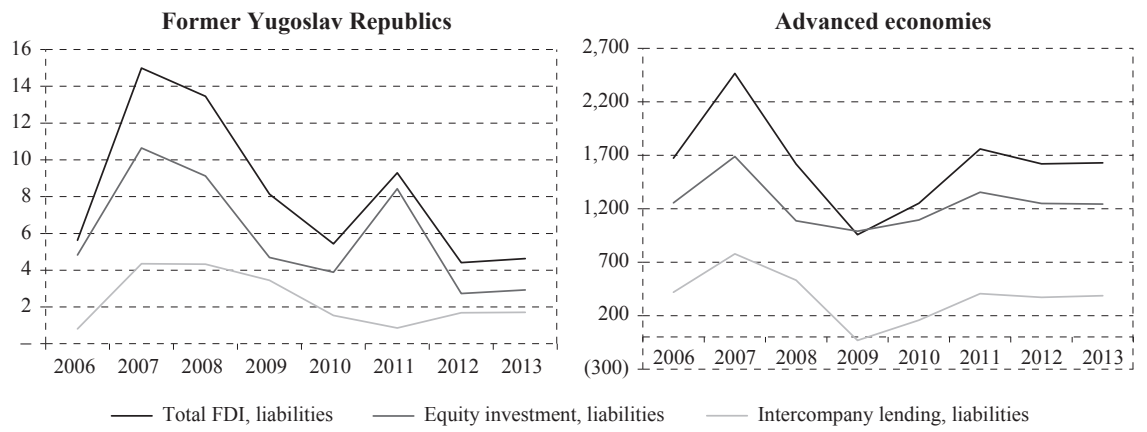

Source of data: IMF.

This post-crisis reversal in capital flows is crucial for this paper. Therefore, it is necessary to compare the inflow of loans, classified as Other investments in the Balance of Payments (BoP) and inflow of ICL in the region (figure A1 in appendix). The assumption is that as a solution of mentioned liquidity issues, foreign affiliates sent additional funds to their subsidiaries in the form of increased ICL. 
During the observed period countries had a very volatile inflow of foreign loans. The majority of them had a significant decline, and some even had a negative inflow, indicating deleveraging by the banks. In addition, it is visible that although countries differ in their levels and dynamics of ICL inflow, there were no precipitous declines or reversals. This is where we can see the FDI nature of ICL and the concern of foreign affiliates for their subsidiaries. Some would argue that additional funds were not provided in sufficient amounts and that they are essentially a loan. However, it must be taken into account that the whole world was faced with the crisis and that MNC had to manage risk on the global level.

The final comparison is the structure of FDI inflow (figure A2 in appendix). First, Croatia and Serbia, in 2008, experienced, at the same time, a plunge in EI and a growth in ICL. Furthermore, the opposing movement of EI and ICL in 2011 in Croatia represents debt-for-equity swap, which changed the nature of the initial transaction and reduced the Croatian external debt by $€ 0.7 b n$ (CNB, 2012). Second, in Macedonia and Bosnia and Herzegovina, the decline of EI was so severe that ICL, although also on a declining trend, had a stabilising role since the decrease was not as steep. Next is Montenegro, where EI peaked because part of their energy sector being privatised in 2009. Finally, in Slovenia, ICL had an adverse effect on FDI inflow in 2009. However, this changed in 2010 and 2011 when it surged. For Kosovo, ICL apparently is not a crucial source of funds, since EI dominates in the overall inflow of FDI.

Based on these movements, we can see that countries differ when it comes to the structure of the total FDI inflow. However, it is noticeable that even in comparison to EI, ICL shows a certain robustness, and that it is a constant source of funds, available when other, more "important", sources of foreign capital come to a halt.

\section{ECONOMETRIC ANALYSIS}

Data availability for this particular topic and the region observed posed several constraints for the econometric analysis. First, the methodology for the compilation of the BoP has changed. Several shifts within its main components made old and newly compiled data incomparable and disenabled their simple combination and creation of longer time series. An additional impediment is that the majority of the observed economies are not EU members and do not have the same obligation to revise past data. For them, relevant BoP data can be found only as of 2007. Second, variables included in the models are not methodologically consistent and available at the same frequency. Therefore, these issues led to a decision to use available annual data from relevant databases, such as IMF, World Bank, Eurostat and WIIW and preserve comparability across countries.

Table 1 lists the starting year from which the data are available for each country. The last year included in the analysis is 2016. It is important to note that for those countries where final data were unavailable, preliminary data from the statistical offices and national banks were used. 
TABle 1

Starting year of the available dataset

\begin{tabular}{|c|c|c|c|c|c|}
\hline Country & Year & Country & Year & Country & Year \\
\hline Albania $^{\mathrm{a}}$ & 2007 & Hungary & 2002 & Poland $^{\mathrm{a}}$ & 2004 \\
\hline $\begin{array}{l}\text { Bosnia and } \\
\text { Herzegovina }^{a}\end{array}$ & 2007 & Kosovo $^{a}$ & 2006 & Romania & 2002 \\
\hline Bulgaria $^{a}$ & 2007 & Latvia & 2002 & Serbia $^{a}$ & 2007 \\
\hline Croatia & 2002 & Lithuania $^{\mathrm{a}}$ & 2004 & Slovakia $^{\mathrm{a}}$ & 2004 \\
\hline Czech R. & 2002 & Macedonia & 2002 & Slovenia & 2002 \\
\hline Estonia & 2002 & Montenegro $^{\mathrm{a}}$ & 2010 & & \\
\hline
\end{tabular}

${ }^{a}$ For some of the variables one year of observation is $N / A$.

The goal of this analysis was to get country-specific estimates for the observed economies, which is why the model averaging is chosen as the primary model. This approach rests on the averaging of the results of several candidate models and gives more robust results (Hansen, 2007). The major benefit is that it does not impose a limitation in the form of one preferred model with predefined variables. Also, it allows the use of the larger set of variables out of which the model creates various combinations and discrete sub-models. In the end, the final estimate is obtained by averaging results across all sub-models, where each receives a proper weight based on the suitable criterion.

The panel data fixed effects model serves as a robustness check for the results obtained by the primary model. For that purpose, we broadened the dataset and populated it with all countries listed in table 1, as they had similar movements in their cross-border financial transactions during the crisis.

The dependent variable is one of the most important macroeconomic indicators, the CAB to GDP. It represents one of the core indicators the United Nations Commission on Sustainable Development uses to observe a sustainable development of the country (UN, 2007). In addition, the importance of this indicator for the observed economies lies in the fact that they are all small and open, and highly dependent on the movement of foreign capital and international trade.

\subsection{DETERMINANTS OF THE MODELS}

The focus of this paper is the effect of ICL on the CAB. Therefore, other determinants will be briefly explained here, while the expected sign and source of data can be found in table A1 in appendix.

All selected variables can be divided into two parts. The choice of the first set was influenced by relevant publications (Aristovnik, 2006; Caivano and Coniglio, 2016; Loayza, Chong and Calderon, 1999).

Lagged values of the CAB to GDP ratio (CAB_lag) - persistence of the CAB deficit exists, and countries need time to overcome shocks. 
Oil balance to GDP ratio $(\mathrm{Oil})$ - oil prices affect the observed economies significantly since all of them are net oil importers.

Trade Openness (Open) - represents the share of a country's foreign trade in GDP.

Macroeconomic uncertainty (Vix) - a proxy for instability in the global markets.

The second part of the variables were chosen based on the intertemporal approach, which seeks to explain movements in the $\mathrm{CAB}$ as a result of the changes in savings and investment (UN, 2008; IMF, 2009). The following identity is crucial for this part, and it breaks savings and investment down into private and government parts:

$$
S-I=S p+S g-I p-I g \rightarrow C A B=(S p-I p)+(S g-I g)
$$

General Government Budget to GDP ratio ( $F . b a l$ ) - budgetary balance of the Government can have a significant impact on the CAB (IMF, 2009).

GDP growth $\left(G D P \_g r\right)$ - a standard measure of the health of the economy.

Unemployment rate (Unem) - its impact on expectation and living standard affects both savings and the investment in the economy.

Foreign direct investments - one of the most important sources for financing $\mathrm{CAB}$ deficits in the transitional economies. The effect of the FDI depends on several factors, and the sign of the coefficient can be both positive and negative. A positive sign on the coefficient can mean that investments created positive effects and increased country's exports or that there is not enough foreign capital inflow to allow a higher $\mathrm{CAB}$ deficit. On the other hand, a negative sign can indicate that FDI produced a higher outflow of capital in the form of income or interest payments, or that the import of equipment increased, which again is beneficial in the long run, since it is assumed that it will create future growth. Therefore, the interpretation, which applies to all of its components, must be country specific.

As noted, for this analysis FDI is broken into EI and ICL. Both variables are expressed in terms of GDP and only those that represent the liabilities of the country were taken into account.

- Intercompany lending (ICL) - The effect of this is the topic of the paper. As a part of FDI, it provides additional funds that countries use to generate future growth. However, as debt position, it can also create an outflow in the form of interest and of principal repayment.

- Equity investment $(E I)$ - Commonly perceived as the only form of FDI, this type of flow brings growth and future improvement of the CAB. However, it can also generate outflows in the form of profit repatriation. 
The idea for the model came from the article by Urosevic, Nedeljkovic and Zildzovic (2012), which observed determinants of the CAB for five CESEE economies. Although the model is similar, the goal of the analysis is different. First, the focus is only on ICL. Second, FDI is broken down into EI and ICL, which makes their effects comparable. Third, the model aims to make a comparative analysis of the economies and show the heterogeneity in the ICL effects among them. Finally, the data used are comparable across countries, which allows a robustness check with a panel regression.

Previously it was mentioned that model averaging, unlike model selection, enables that all relevant information is taken into account by averaging the results of the candidate sub-models. Its resulting estimates consider both the uncertainty and the bias that exist in each of the sub-models, which makes them more robust. However, the crucial element necessary for the optimal results is the criterion that assigns the weights to each of the sub-models. Two methods are proposed in the literature, Bayesian and frequentist. While the first relies on the subjective determination of probabilities and weights, the second one uses well-known criteria. Although many criteria can be found in the literature, many of them exclude heteroscedasticity and non-nested setup, which makes them unsuitable for the analysis of the CAB (Urosevic, Nedeljkovic and Zildzovic, 2012). Therefore, as proposed by Hansen and Racine (2012) for these conditions the best results are given by jackknife model averaging (JMA), which selects the weights by minimising a leave-one-out cross-validation criterion and provides an estimator that is an asymptotic equivalent to the lowest expected squared error. Liu (2012) further adjusted this model and made it applicable for the time series analysis, and this is the approach that will be used in this paper.

The regression model used can be described as follows ${ }^{1}$ :

$$
\begin{gathered}
y_{n}=X_{n} \beta+u_{n} \\
E\left(u_{n} \mid X_{n}\right)=0 \\
E\left(u_{n}^{2} \mid X_{n}\right)=\sigma^{2}\left(X_{n}\right)
\end{gathered}
$$

where $y_{n}$ is the CAB to GDP ratio, $X_{n}$ is the vector of independent variables, and $\beta$ is the ordinary least square estimator. Also, $u_{n}$ is the error term that does not preclude heteroscedasticity. If there is an assumption about $M$ number of models, $\mathrm{m}=1,2 \ldots \mathrm{M}$, where each model is a sub-model and unique combination of independent variables $X_{n}$, then for each model there is a set of linear estimators that can be written as:

$$
\tilde{\beta}_{m}=\left(X_{m}^{\prime} X_{m}\right)^{-1} X_{m}^{\prime} y
$$

\footnotetext{
${ }^{1}$ Description of the model is taken from Urosevic, Nedeljkovic and Zildzovic (2012).
} 
The final estimate of the model is a weighted average of all sub-model estimations:

$$
\tilde{\beta}_{m}=\sum_{m=1}^{M} \omega_{m} \tilde{\beta}_{m}
$$

where $\omega_{m}$ is a set of non-negative weights, that sum up to one. As previously mentioned JMA selects the weights by minimizing the leave-one-out cross-validation criterion (CV), defined as:

$$
C V_{n}(\omega)=\frac{1}{N} \omega^{\prime} \tilde{u}_{-i}^{\prime} \tilde{u}_{-i} \omega
$$

where $\tilde{u}_{-i}=\left(\tilde{u}_{-i, 1}, \ldots, \tilde{u}_{-i, M}\right)$ is a $N x M$ matrix of leave-one-out residuals, where $\tilde{u}_{-i, m}$ are the residuals from the $\mathrm{m}^{\text {th }}$ model estimated by least squares, excluding the $\mathrm{i}^{\text {th }}$ observation. Finally, the JMA chooses $\omega_{m}$ which minimizes the $C V_{n}(m)$.

\subsubsection{Model averaging results}

Before running the JMA, the stationarity was checked. For each variable within each country, a KPSS test was done, as it shows better performance on small samples (Bart, Franses and Ooms, 1998). Its null hypothesis states that the observed time series is stationary. Results can be found in table A2 in appendix, and for all, except for Montenegrin GDP growth, we failed to reject the null. For this country the problem is the limited sample availability since the complete data set is available only as of 2010. Also, the JMA gave insignificant coefficients for Montenegro, which is why this country is excluded from the subsequent analysis.

Previously it was noted that only the effects of ICL would be in focus and heterogeneity across the economies (table 2). Results obtained are significant, and for all, except for Kosovo, the effect is negative. Remaining variables and their p-values can be found in table A3 in appendix and can serve for future analysis. Furthermore, in order to understand better how important ICL was in comparison to other variables within the specific economy, the standardised coefficients are also included in the analysis. Those were calculated as the product of the estimated coefficient and the ratio between the independent's and dependent's variable standard deviations.

TABLe 2

\begin{tabular}{|c|c|c|}
\hline Country & ICL & p-value \\
\hline Bosnia and Herzegovina & -1.868 & $0.022 * *$ \\
\hline Croatia & -0.802 & $0.002 * * *$ \\
\hline Kosovo & 3.837 & $0.003 * * *$ \\
\hline Macedonia & -2.818 & $0.000^{* * *}$ \\
\hline Serbia & -3.488 & $0.008 * * *$ \\
\hline Slovenia & -0.650 & $0.004 * * *$ \\
\hline
\end{tabular}

Jackknife model averaging, ICL coefficients, by country

** Significance at 5\% level, *** significance at 1\% level. 
The negative values of the estimates imply that for those economies that have persistent current account deficits, such as Bosnia and Herzegovina, Macedonia and Serbia, an increase in the share of ICL in GDP is followed by the growth of the CAB deficit in the GDP. Inversely, a similar movement can be spotted for Slovenia and Croatia, which in recent years have had a surplus in the CAB, followed by the negative inflow of total FDI. The only positive effect of ICL on CAB is derived for Kosovo, and the possible explanation is that since the inflow of ICL was at a very low level, it did not provide additional funds that would finance a higher share of CAB deficit in GDP.

As for the magnitude, the strongest negative effect is for Serbia, then Macedonia and Bosnia and Herzegovina, while Slovenia and Croatia demonstrate a somewhat weaker effect. The magnitude of the results serves as an indicator of the differences that exist among the observed countries in their level of dependence on foreign investment inflows.

Furthermore, we include standardised coefficients into the analysis to find the relative importance each variable has within the country (table 3). Again, we can note that for all observed economies, ICL had a high contribution to the CAB. However, it is the largest for Kosovo and Serbia. As previously noted, the positive sign for Kosovo signals an insufficient inflow of ICL. Here, the stock of EI is at a low level, and foreign investors do not have an incentive to send additional ICL. Furthermore, the negative value of the EI coefficient proves that this is the FDI component that serves as a source for $\mathrm{CAB}$ financing. For Serbia, it is interesting to see that, when observed separately, ICL has a negative effect, while EI has a positive impact on the $\mathrm{CAB}$, which is a result of successful privatisations that induced export. Therefore, here we can argue that in Serbia ICL is sent as a constant fuel that allows further growth of the initial investment and finances the CAB deficit, caused by the import of intermediary goods and equipment.

\section{TABLE 3}

Jackknife model averaging, standardised coefficients, by country

\begin{tabular}{|c|c|c|c|c|c|c|}
\hline Variable & B\&H & Croatia & Kosovo & Macedonia & Serbia & Slovenia \\
\hline$I C L$ & -0.482 & -0.270 & 1.236 & -0.890 & -0.688 & -0.154 \\
\hline$C A B \_l a g$ & 0.174 & 0.301 & -0.081 & 0.519 & & 0.367 \\
\hline$E I$ & -0.879 & -0.019 & -0.800 & -0.375 & 0.202 & -0.105 \\
\hline Oil & 0.597 & 0.231 & -0.203 & -0.151 & 0.282 & 0.259 \\
\hline Open & & 0.099 & -0.033 & 0.327 & & 0.257 \\
\hline$G D P \_g r$ & 0.088 & -0.542 & -0.664 & 0.717 & -0.187 & -0.152 \\
\hline Unem & 0.369 & 0.289 & -0.031 & -0.039 & 0.495 & 0.281 \\
\hline F.bal & -0.151 & 0.119 & 0.331 & & 0.451 & 0.002 \\
\hline Vix & -0.233 & 0.127 & -0.405 & -0.916 & -0.485 & \\
\hline
\end{tabular}

Bolded figures indicate the strongest effect.

For Macedonia and Bosnia and Herzegovina, the contribution of ICL is also among the highest ones. For Bosnia and Herzegovina, which struggles to attract 
FDI (U.S. Department of State, 2015), the highest contribution is derived for EI. That result signals that this country still needs to attract the critical amount of this type of FDI and that those already obtained had an important effect on the financing of $\mathrm{CAB}$ deficit. After that happens, the relative significance of ICL might increase. For Macedonia the highest contributions are for VIX and ICL, which can suggest that this is a country highly dependent on foreign capital and highly sensitive to the movements of the world economy. For Slovenia and Croatia, the ICL contribution is not as important as for the mentioned three countries. Additionally, the importance of other variables is somewhat balanced. That may indicate that their $\mathrm{CAB}$ is not overly dependent on one particular variable.

The analysis can be further broadened when we observe how the contribution of ICL to the CAB changed over the years (figure A3 in appendix). We can see that for Serbia and Macedonia, the strength of the effect fluctuates but remains high, which is in line with the previously stated high dependency on foreign investment inflow. However, for Bosnia and Herzegovina, this contribution declines and can be explained by the very slow increase in the EI inflow, and subsequent drop in the ICL inflow. As previously noted, its primary concern should be attracting EI. In Slovenia and Croatia, the contribution was modest across years and became positive when countries started achieving a surplus in the $C A B$, and this is also in line with the previous analysis of the results.

\subsection{PANEL REGRESSION FIXED EFFECTS}

The second model serves as a robustness check of the results obtained the JMA. This model uses the same variables as JMA, however, here it was used on an unbalanced panel with 17 economies (table 1). The estimated model can be written as:

$$
y_{\text {in }}=\alpha+X_{\text {in }} \beta+\gamma t_{i}+u_{\text {in }}
$$

where $y_{i n}$ is the CAB to GDP ratio, $X_{i n}$ is the vector of independent variables, $t_{i}$ is the trend dummy, and $\beta$ and $\gamma$ are coefficient estimates. Also, $u_{i n}$ is the error term.

The unit root tests were done for the whole dataset. Since it failed to reject its existence for dependent and several control variables, the trend dummy variable was added to control for the trend. Results obtained before and after adding the trend dummy (table 4) did not differ substantially, which is why we decided to accept the results of the panel regression and continue with the analysis.

Results in table 4 show that the ICL effect is significant, while the same is not true for that of EI. One way to explain this is that once initial investment happens in the form of EI, foreign investors opt to send additional funds to the CESEE region in the form of ICL. This supports the view that since the crisis started, the FDI inflow has been sustained by the ICL in the observed countries. The negative sign is also expected, since FDI in the transitional economies represents funds used for financing the $\mathrm{CAB}$ deficit. 
Panel regression results, with and without trend dummy

\begin{tabular}{|c|c|c|c|c|}
\hline \multirow{2}{*}{ Coefficients } & \multicolumn{2}{|c|}{ Without trend dummy } & \multicolumn{2}{|c|}{ With trend dummy } \\
\hline & Estimate & p-value & Estimate & p-value \\
\hline$I C L$ & -0.372 & $0.0291 * *$ & -0.368 & $0.0306 * *$ \\
\hline$E I$ & -0.012 & 0.8576 & -0.011 & 0.8787 \\
\hline Oil & 0.665 & $0.0044 * * *$ & 0.634 & $0.0047 * * *$ \\
\hline Open & 0.186 & $0.0000 * * *$ & 0.176 & $0.0000 * * *$ \\
\hline$G D P \_g r$ & -0.487 & $0.0000 * * *$ & -0.469 & $0.0000 * * *$ \\
\hline Unem & 0.249 & $0.0005 * * *$ & 0.253 & $0.0007 * * *$ \\
\hline F.bal & 0.130 & 0.3883 & 0.132 & 0.3764 \\
\hline$V I X$ & -0.008 & 0.3651 & -0.008 & 0.3483 \\
\hline Dummy trend & & & 0.0004 & 0.7613 \\
\hline
\end{tabular}

** Significance at $5 \%$ level, *** significance at $1 \%$ level.

\section{CONCLUSION}

\subsection{SUMMARY OF FINDINGS}

The assumption from which this analysis was derived is that in the crisis periods, countries that are dependent on foreign capital can face many problems if a sudden stop occurs. For the observed economies, September 2008 marked the beginning of the crisis and the sudden decline in the inflow of foreign funds.

As noted, the financial sector in the CESEE is mostly foreign owned, and precrisis growth rates were greatly fuelled by the loans provided by the major banking groups. Additionally, the crisis affected the private sector. However, those that were foreign owned got help in the form of ICL. Although it shares some characteristics with commercial banking loans, ICL is an FDI. The core element of FDI is the long-term commitment that an MNC makes when it invests initial equity. Afterwards, the subsidiary is expected to function on its own and generate profits. Additional funds can be sent because there are either growth opportunities or problems. After the crisis, growth opportunities became rare, so we assume that ICL was sent as a support.

Reasons why the ICL and not some other form of capital was sent can be observed from the risk management point of view. As explained before, for an MNC they provide flexibility, an additional channel of control and lower costs. The worldwide crisis and perception of risk in the region made ICL a reasonable option and influenced the amount sent. An additional element that proves this point is the debt-for-equity swaps. If we look again at the structure of the FDI for the observed economies (figure A2 in appendix), movements in the FDI inflows show the existence of several debt-for-equity swaps, which imply risk management strategy. If the investors perceive the economy to be risky, and they want to keep flexibility in their capital flows, they can initially send funds in the form of the loan, and then, depending on the situation transform it into equity or pull it back. In these economies, all plunges in ICL were followed by the surges in $\mathrm{EI}^{2}$.

\footnotetext{
${ }^{2}$ In Croatia in 2015, debt-for-equity swaps prevented even larger decline of total FDI since EI plunged due to value adjustments and negative reinvestment of earnings (EBL News, 2016).
} 
Furthermore, if we add that the majority of investments came into the region as the brownfield investments and that this source of EI has almost dried up, then we can note that ICL is an FDI component that sustains the total inflow. Therefore, if we envision ICL as funds that fuel previously established direct investment and are an "introductory" form of current EI, it is easy to comprehend the magnitude of the effect derived in the model and how the benefits of this FDI component are created.

Finally, the opponents of ICL can state that the outflow of capital through interest payments is a drain on the economy and that it increases external debt. The former is not true for the observed economies since they have not experienced a substantial outflow of funds through ICL-based interest payments. As for the latter, debt exposures toward affiliated companies are considered to be more sustainable because of the FDI relationship. Furthermore, the frequently recorded debt-forequity swaps have the same effect on external debt level as debt forgiveness. Overall, this debt is more stable.

\subsection{POLICY IMPLICATIONS AND RECOMMENDATIONS}

The goal of the paper was to observe whether or not the ICL inflow had a significant effect on the observed economies. Two models that were employed indicated that it did. For the majority of countries, that effect is negative, which is not surprising since in many of the observed economies domestic savings are not sufficient to finance investments, and additional funds must be imported. Therefore, when deciding which policy to pursue, an increase in the CAB deficit because of the surge in investment should not be considered problematic, since, in the long run, it will generate growth.

The first set of results obtained by JMA allows cross-country comparison and indicates which countries are more dependent on foreign financing, while the second set, with the standardised coefficients, allows country-specific analysis and shows areas where policy actions are most important.

Essentially, when it comes to the policy implications for ICL, one crucial element must be taken into account. ICL are conditioned with the existence of the direct investment relationship, and its inflow is dependent on the policies that promote EI. Therefore, countries should concentrate on the implementation of policies that attract it, and consequently, inclusion in the multinational networks will bring higher performance (Alfaro and Chen, 2010).

Therefore, the set of recommendations should be foremost concerned with the attraction of new EI. In the past, foreign investors were mostly interested in privatisation and brownfield investments. Since the potential for those is decreasing, it would be beneficial to promote greenfield investments. Furthermore, as noted by Estrin and Uvalic (2016), FDI in the region was mostly focused on the financial sector, and not enough in the manufacturing, which may be a reason why these countries still are not able to integrate better into the global market and benefit from the higher export potential. In addition to that, for the majority of these economies, 
full integration into the European Union would bring significant benefits. One of the biggest ones would be an improvement in the institutional quality that these economies lack. The severe effect of this is the increased perception of risk investors have, that ultimately undermines the higher inflow of foreign capital (Estrin and Uvalic, 2013).

Finally, when giving a policy recommendation, one must take into account the other side of the ICL. Even though in the paper the focus was on the identification of the benefits from ICL, it must not be forgotten that it can induce transfer pricing. That is why the implementation of policies and participation in the initiatives such as the BEPS are of utmost importance. Ultimately, this can lead to a situation in which ICL is no longer perceived as a rent-seeking transaction and starts to be perceived as a significant advantage to those companies that are a part of the FDI circle.

\subsection{LIMITATIONS OF THE STUDY AND FUTURE RESEARCH POSSIBILITIES}

Certain limitations of the study exist, and they are mostly concerned with the availability of the data. The issue of the short time series may have impeded an econometric analysis that would have yielded more convincing results. The methodological changes and difficulties in finding relevant quarterly data further complicated the analysis. Additionally, it restrained the full potential of the model averaging technique, since the number of variables had to align with the number of observations available.

When we observe the region of interest, only two countries are members of the EU and have more stringent rules when it comes to the availability of data sets. Others choose whether to comply with them, as it is not compulsory. Since in this paper the emphasis was on the comparability across economies, the same number of variables was used for all models. Therefore, for those countries where longer series are available, the data limitation can be overstepped, and a more detailed analysis with additional variables can be made. Additionally, this can also provide a solid ground for other economies when the longer time series become available. Finally, the analysis does not have to stop at the effect of ICL, and the data in the appendix can also be a starting point for further research.

\section{Disclosure statement}

No potential conflict of interest was reported by the author. 
TABLE A1

Variable description

Variable

Lagged values of the $\mathrm{CAB}$

to GDP ratio ( $\left.C A B \_l a g\right)$

Oil balance to GDP ratio

(Oil)

\section{Expected sign Source}

Vienna Institute for International Economic Studies (WIIW)

Eurostat, International Trade in Mineral fuels, lubricants and related materials (SITC Rev. 4) served as a proxy

Trade Openness (Open)

Macroeconomic uncertainty (Vix)

Ambiguous

World Bank

Federal Reserve Bank of St. Louis, CBOE Volatility Index, \% change from a year ago, annual, not seasonally adjusted

General Government Budget

to GDP ratio (F.bal)

GDP growth $\left(G D P \_g r\right)$ $+\quad$ WIIW

Unemployment rate (Unem)

Foreign direct investments:

Intercompany lending $(I C L)$

Equity investment $(E I)$

\section{TABLe A2}

Jackknife model averaging, unit root tests results

\begin{tabular}{|c|c|c|c|c|c|c|c|}
\hline \multirow{2}{*}{ Variables } & B\&H & Croatia & Kosovo & Macedonia & Montenegro & Serbia & Slovenia \\
\hline & \multicolumn{7}{|c|}{ KPSS test results } \\
\hline$C A B$ & $0.392 *$ & $0.440^{*}$ & 0.107 & 0.306 & 0.326 & 0.416 & $0.729 * *$ \\
\hline$I C L$ & $0.390 *$ & 0.230 & 0.302 & 0.185 & 0.144 & $0.347^{*}$ & 0.131 \\
\hline$E I$ & 0.251 & 0.282 & 0.332 & 0.223 & & 0.205 & $0.348^{*}$ \\
\hline Oil & 0.211 & 0.137 & 0.314 & 0.175 & 0.287 & 0.407 & 0.148 \\
\hline Open & 0.314 & $0.363 *$ & 0.231 & $0.389 *$ & 0.089 & $0.698 * *$ & $0.391 *$ \\
\hline$G D P \_g r$ & 0.153 & 0.260 & 0.306 & 0.144 & $1.235 * * *$ & 0.186 & 0.239 \\
\hline Unem & 0.135 & 0.292 & 0.261 & $0.560 * *$ & $0.514 * *$ & 0.196 & $0.382^{*}$ \\
\hline F.bal & 0.144 & 0.124 & $0.349 *$ & 0.226 & 0.253 & 0.165 & 0.267 \\
\hline Vix & 0.085 & 0.050 & 0.097 & 0.050 & & 0.085 & 0.050 \\
\hline
\end{tabular}

The null hypothesis for KPSS is existence of stationarity, and it is rejected if obtained value is above the critical. Critical values are 0.739 (*** significant at 1\%), 0.463 (** significant at 5\%), 0.347 (* significant at $10 \%$ ). 


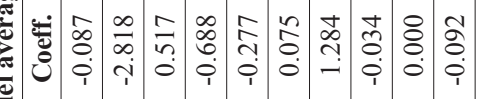

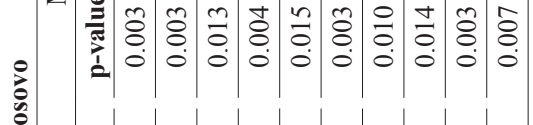

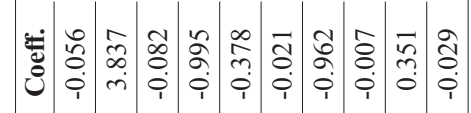

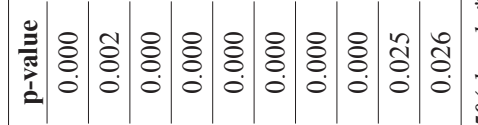

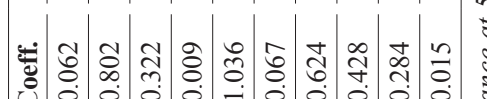
$\approx$ 3

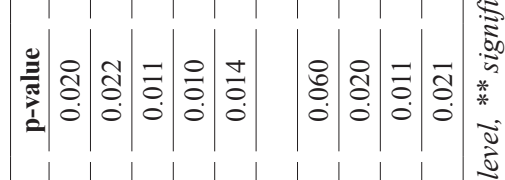

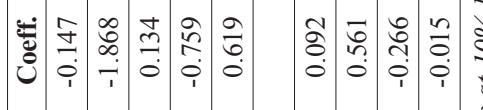

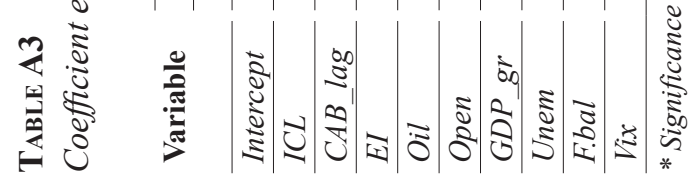




\section{Figure A1}

Other investments and intercompany lending, liabilities, \% of GDP

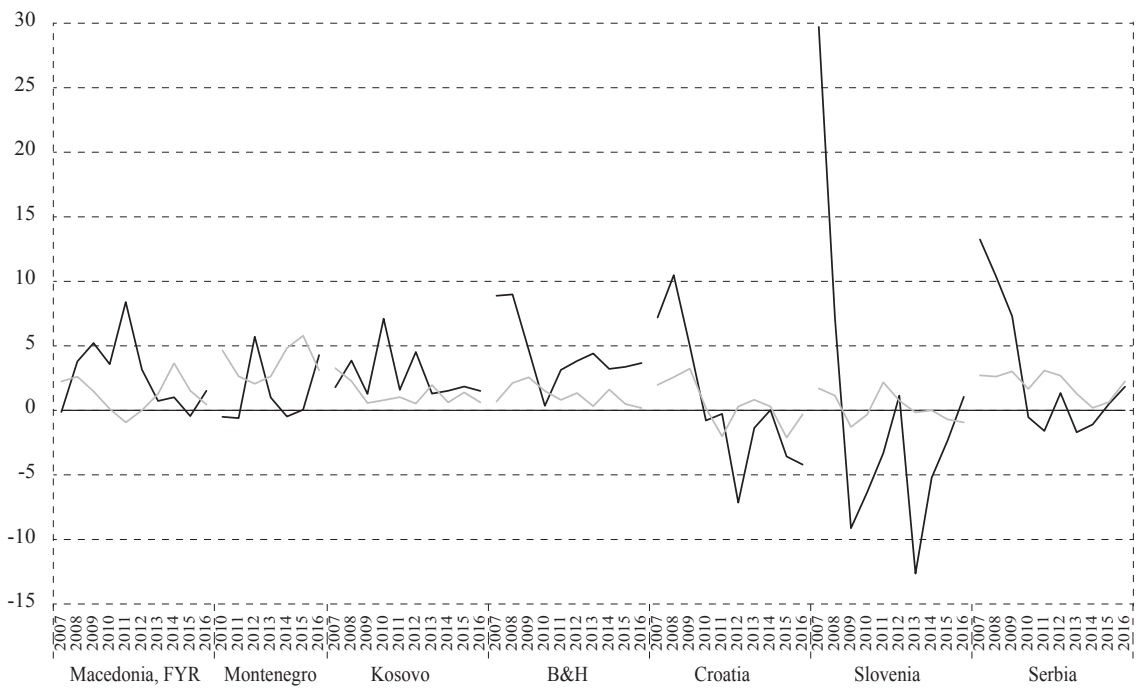

Source of data: WIIW.

— Other liabilities, \% GDP — Intercompany lending, \% GDP

\section{Figure A2}

The structure of FDI, inflow, in bn USD

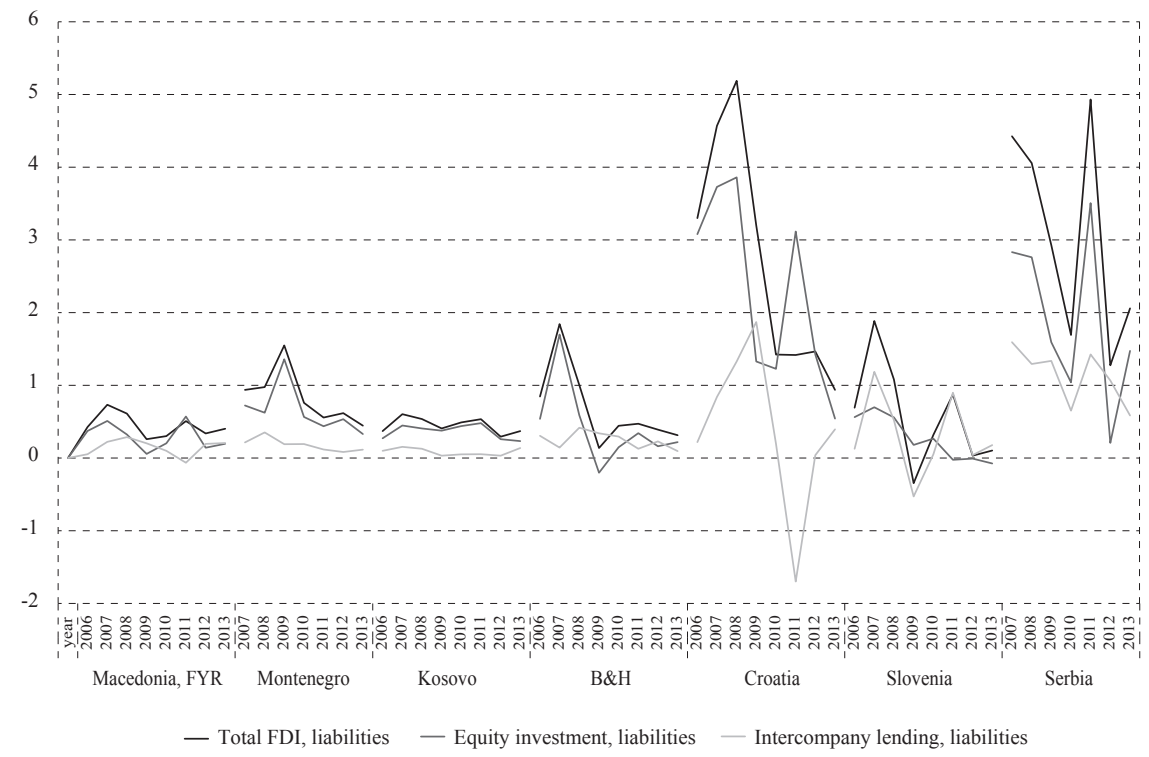

Source of data: IMF. 
Figure A3

The contribution of ICL to the CAB, two and three-year averages, \% of GDP
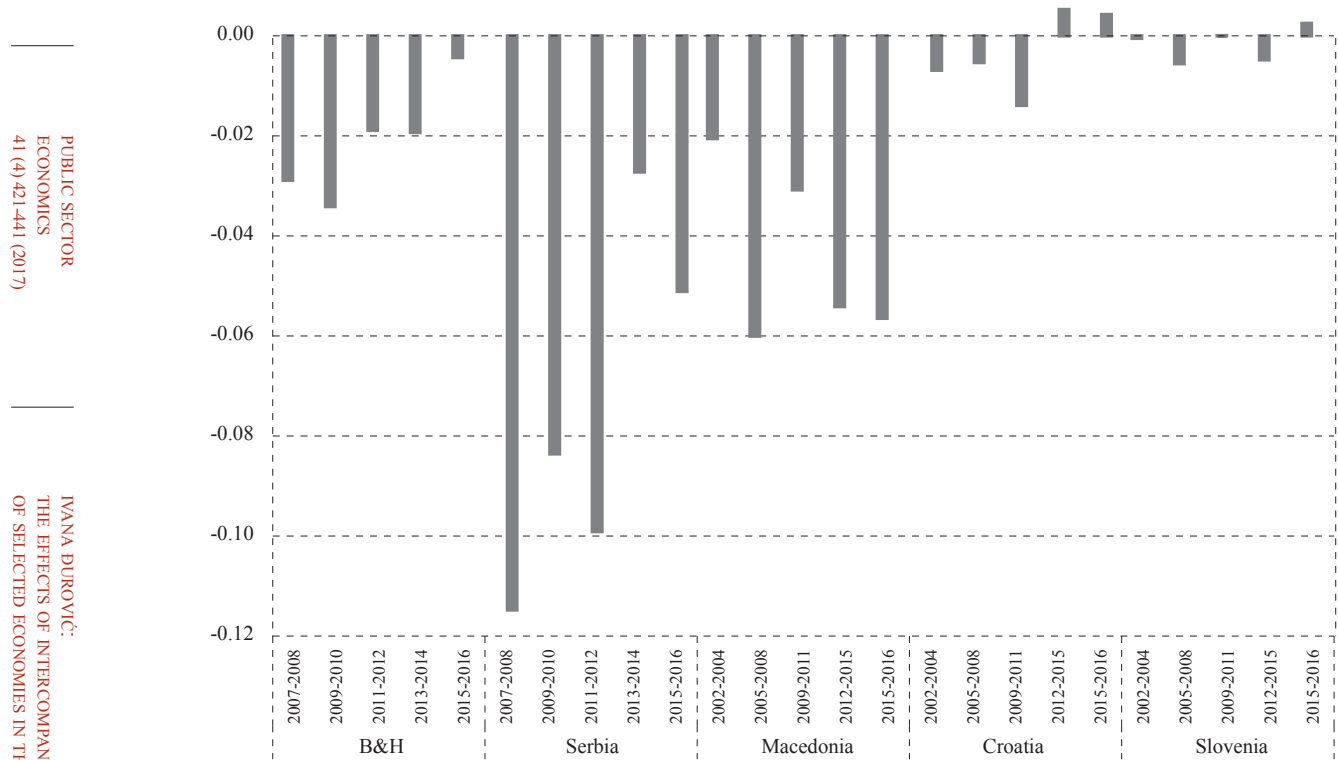

Source: Results of the author. 


\section{REFERENCES}

1. Alfaro, L. and Chen, M. X., 2010. Surviving the Global Financial Crisis: Foreign Direct Investment and Establishment Performance. Harvard Business School BGIE Unit Working Paper, No. 10-110. Available at: <https://papers. ssrn.com/sol3/papers.cfm?abstract_id=1623831>.

2. Aristovnik, A., 2006. Current Account Sustainability In Selected Transition Countries. William Davidson Institute Working Papers Series, WP844. Available at: $<$ https://ideas.repec.org/p/wdi/papers/2006-844.html $>$.

3. Barrios, S. [et al.], 2009. International Taxation and Multinational Firm Location Decisions. Brussels, Belgium: European Commission, DirectorateGeneral for Economic and Financial Affairs. Available at: $<$ http://ec.europa. eu/economy_finance/publications/publication14169_en.pdf $>$.

4. Bart, H., Franses, P. H. and Ooms, M., 1998. Generalizations of the KPSS-Test for Stationarity. Econometric Institute Report, No. 9802/A. Available at: $<$ http://citeseerx.ist.psu.edu/viewdoc/download?doi=10.1.1.199.9956\&rep=r ep1\&type $=$ pdf $>$.

5. Bevan, A. A. and Estrin, S., 2004. The Determinants of Foreign Direct Investment into European Transition Economies. Journal of Comparative Economics, 32(4), pp. 775-87. doi: 10.1016/j.jce.2004.08.006

6. Borensztein, E., De Gregorio, J. and Lee, J-W., 1998. How Does Foreign Direct Investment Affect Economic Growth? Journal of International Economics, 45(1), pp. 115-135. doi: 10.1016/S0022-1996(97)00033-0

7. Buettner, T. and Wamser, G., 2007. Intercompany Loans and Profit ShiftingEvidence from Company-Level Data. CESifo Working Paper Series, No. 1959. Available at: <https://papers.ssrn.com/sol3/papers.cfm?abstract_id= 981120>.

8. Caivano, G. and Coniglio, N. D., 2016. Long-Run Drivers of Current Account Imbalances in the EU: The Role of Trade Openness. Series Working Paper, No. 03-2016. Available at: $<$ https://ideas.repec.org/p/bai/series/series_wp_032016.html>.

9. CNB, 2012. Annual Report 2011. Zagreb: Croatian National Bank. Available at: <http://www.hnb.hr/documents/20182/122227/h-gi-2011.pdf/2b288321d5cd-44d3-86cf-cbddb44f5380>.

10. Devereux, M. P. and Griffith, R., 1998. Taxes and the Location of Production: Evidence from a Panel of US Multinationals. Journal of Public Economics, 68(3), pp. 335-367. doi: 10.1016/S0047-2727(98)00014-0

11. DiMauro, F. 2000. The Impact of Economic Integration on FDI and Exports: A Gravity Approach. CEPS Working Document, No. 156. Brussels: CEPS.

12. EBL News, 2016. FDI in Croatia in 2015 Plunge to EUR 128mn. EBL News, April 14. Available at: <https://eblnews.com/news/croatia/fdi-croatia-2015plunge-eur-128mn-17689>.

13. ECB, 2012. Deleveraging and the Role of Central Banks. Available at: $<$ https://www.ecb.europa.eu/press/key/date/2012/html/sp121026_1.en.html>. 
14. Estrin, S. [et al.], 2009. The Effects of Privatization and Ownership in Transition Economies. Journal of Economic Literature, 47(3), pp. 699-728. doi: 10.1257/jel.47.3.699

15. Estrin, S. and Uvalic, M., 2013. Foreign Direct Investment into Transition Economies: Are the Balkans Different? LEQS Paper, No. 64. Available at: $<$ https://papers.ssrn.com/sol3/papers.cfm?abstract_id=2293100>.

16. Estrin, S. and Uvalic, M., 2016. Foreign Direct Investment in the Western Balkans: What Role Has It Played During Transition? Comparative Economic Studies, 58(3), pp. 455-483. doi: 10.1057/ces.2016.10

17. Gardo, S. and Reiner, M., 2010. The Impact of the Global Economic and Financial Crisis on Central, Eastern and South-Eastern Europe: A Stock-Taking Exercise. ECB Occasional Paper, No. 114. Available at: <https://papers. ssrn.com/sol3/papers.cfm?abstract_id=1626117>.

18. Hansen, B. E., 2007. Least Squares Model Averaging. Econometrica, 75(4), pp. 1175-1189. doi: 10.1111/j.1468-0262.2007.00785.x

19. Hansen, B. and Racine, J., 2012. Jackknife Model Averaging. Journal of Econometrics, 167(1), pp. 38-46. doi: 10.1016/j.jeconom.2011.06.019

20. Hebous, S. and Weichenrieder, A. J., 2010. Debt Financing and Sharp Currency Depreciations: Wholly versus Partially-Owned Multinational Affiliates. Review of World Economics / Weltwirtschaftliches Archiv, 146(2), pp. 281302. doi: 10.1007/s10290-010-0055-9

21. Hermes, N. and Lensink, R., 2003. Foreign Direct Investment, Financial Development and Economic Growth. The Journal of Development Studies, 40(1), pp. 142-163. doi: 10.1080/00220380412331293707

22. Herrmann, S. and Mihaljek, D., 2010. The Determinants of Cross-Border Bank Flows to Emerging Markets: New Empirical Evidence on the Spread of Financial Crises. BIS Working Papers, No. 315. Available at: $<\mathrm{http}: / / \mathrm{www}$. bis. org/publ/work315.pdf>.

23. IMF, 2009. Balance of Payments and International Investment Position Manual. Washington D.C.: International Monetary Fund.

24. Li, X. and Liu, X., 2005. Foreign Direct Investment and Economic Growth: An Increasingly Endogenous Relationship. World Development, 33(3), pp. 393-407. doi: 10.1016/j.worlddev.2004.11.001

25. Lim, E.-G., 2001. Determinants Of, and the Relation Between, Foreign Direct Investment and Growth: A Summary of the Recent Literature. Washington D.C.: International Monetary Fund.

26. Liu, C-A., 2012. A Plug-In Averaging Estimator for Regressions with Heteroskedastic Errors. University of Wisconsin Madison mimeo.

27. Loayza, N., Chong, A. and Calderon, C. A., 1999. Determinants of Current Account Deficits in Developing Countries. World Bank Policy Research Working Paper, No. 2398. Available at: $<$ https://papers.ssrn.com/sol3/papers. cfm?abstract_id=630771>. 
28. Resmini, L., 2000. The Determinants of Foreign Direct Investment in the CEECs: New Evidence from Sectoral Patterns. Economics of Transition, 8(3), pp. 665-689. doi: 10.1111/1468-0351.00060

29. Starnawska, S., 2015. International Business Risk Management and the Emerging Market Crises as Challenges for the UN Global Compact in: L. Leonard and M. Alejandra Gonzalez-Perez, ed. Beyond the UN Global Compact: Institutions and Regulations, pp. 21-46. doi: 10.1108/S2051503020150000017009

30. Stewart, J. C., 1977. Multinational Companies and Transfer Pricing. Journal of Business Finance \& Accounting, 4(3), pp. 353-371. doi: 10.1111/j.1468-5957. 1977.tb00719.x

31. UN, 2007. Indicators of Sustainable Development: Guidelines and Methodologies. New York: United Nations.

32. UN, 2008. System of National Accounts 2008. New York: United Nations [u.a.].

33. Urosevic, B., Nedeljkovic, M. and Zildzovic, E., 2012. Jackknife Model Averaging of the Current Account Determinants. Panoeconomicus, 59(3), pp. 267-281. doi: 10.2298/PAN1203267U

34. U.S. Department of State, 2015. Bosnia and Herzegovina, Investment Climate Statement. Available at: $<$ https://www.state.gov/documents/organization/ 241701.pdf>. 